\title{
EFFECT OF RICE BRAN OIL ON THE LIPID PROFILE OF MILD-MODERATE HYPERCHOLESTEROLEMIC MALE AGE 19-55 YEARS OLD
}

\author{
Noor Diah Erlinawati, ${ }^{1}$ Samuel Oetoro, ${ }^{2}$ Dwirini R Gunarti ${ }^{3}$ \\ 1 Department of Nutrition, Faculty of Medicine, University of Bengkulu, W.R. Supratman, Bengkulu, Indonesia \\ 2 Department of Nutrition, Faculty of Medicine, Universitas Indonesia, Jakarta, Indonesia \\ 3 Department of Biochemistry, Faculty of Medicine, Universitas Indonesia, Jakarta, Indonesia
}

Abstract-Introduction: Adult individuals in Indonesia showed changes in diet and lack of physical activity, therefore increasing the risk of hypercholesterolemia and obesity. One of nutritional therapy for hypercholesterolemia is rice bran oil, which contains active substances that works synergistically in controlling lipid profile. The substances are gamma-orzanol, phytosterols, and vitamin $\mathrm{E}$ isomers (tocotrienol and tocopherol).

Methods: A clinical trial was conducted for 4 weeks in City Hall of Jakarta on 20 males, age 1955 years old, with mild-moderate hypercholesterolemia, to assess lipid profile improvement of the supplementation of rice bran oil $45 \mathrm{ml} /$ days compared to $15 \mathrm{ml} /$ days without changing eating patterns.

Results: After 4 weeks of intervention, there was significant difference in total cholesterol level between both groups $(p=0.049)$. In the group that received $45 \mathrm{ml} /$ days of rice bran oil, total cholesterol level decreased $14 \%$, and in the group of $15 \mathrm{ml} /$ days total cholesterol level decreased $7.8 \%$. The reduction of LDL and triglycerides and the increase of HDL were not significantly different between both groups $(p>0,05)$. There was no significant changes of body weight in both groups.

Conclusion: This study showed that consumption of $45 \mathrm{ml} /$ days rice bran oil led to better improvements in lipid profiles compare to 15 $\mathrm{ml} /$ days. It has been demonstrated that gamma oryzanol and plant sterols in rice bran oil have the capability to remove cholesterol from bile salt micelles, thus decreasing cholesterol absorption in intestine.

Keywords: rice bran oil, gamma-oryzanol, hypercholesterolemia, lipid profile

\section{INTRODUCTION}

Cardiovascular disease has a tendency to increase in developing countries as a result of lifestyle changes. ${ }^{1}$ According to WHO data of noncommunicable diseases in year 2010 in Indonesia, the prevalence of elevated cholesterol level was $35.1 \%$ and was higher in women $(37.2 \%)$ than in men $(32.8 \%)^{2}$ Male adults are at risk for suffering hypercholesterolemia and central obesity due to lifestyle changes. ${ }^{3,4}$ This condition may lead to increased risk of metabolic syndrome, hypertension, diabetes mellitus, obesity and other chronic diseases. $^{4-6}$

Nutritional therapy became the first pillar as part of lifestyle intervention in hypercholesterolemia. Phytosterol, which is one of functional food, has been recommended by the National Cholesterol Education Program (NCEP) for controlling lipid profiles. ${ }^{7}$ Rice bran oil contains gamma-oryzanol, phytosterols, and vitamin $\mathrm{E}$ (tocotrienols and tocopherols), which are known as unsaponifiables fractions. Gamma-oryzanol consists of ferulic acid and phytosterol esters, which are structurally and functionally similar to cholesterol. Both substances can reduce the absorption of cholesterol in the intestine as competitive inhibitors. Unsaponifiable fractions of rice bran oil act synergistically in controlling blood lipid profile. The composition of fatty acids in rice bran oil are closest to the recommendation of the American Heart Association (AHA). ${ }^{8-13}$

There were some studies done by Raghuram $^{14}$, Kuriyan ${ }^{15}$, Rajnarayana ${ }^{16}$ and Eady ${ }^{13}$ which showed rice bran oil effect in improving lipid profile in hypercholesterolemic patients. Rice bran oil products are currently widely recommended by clinicians because of their benefits of preventing cardiovascular diseases. Earlier studies mostly used $300 \mathrm{mg} /$ day dose of gamma-oryzanol or 50 grams of rice bran oil, which were included in the daily diet or cooking oil. ${ }^{13,17}$ However no studies regarding the effective amount or dose of rice bran oil in daily consumption without changing food 
intake on lipid profiles of hypercholesterolemic patients has been done yet. This study aimed to assess the lipid profile improvement after intake of different amount of rice bran oil without changing the eating patterns.

\section{METHODS}

\section{Subjects}

A total of 26males with hypercholesterolemia, age 19-55 years old, were recruited for the study. Inclusion criteria were cholesterol levels 200-300 $\mathrm{mg} / \mathrm{dl}$ and body mass index $20-30 \mathrm{~kg} / \mathrm{m}^{2}$. The exclusion criteria were any consumption of cholesterol-lowering drugs, steroids and other drugs that affect lipid metabolism; smoking more than 10 cigarettes/day; taking weight loss program or consuming appetite inhibitor drugs; taking supplements containing phytosterol; have gastrointestinal, thyroid, heart, liver and kidney diseases which are determined by medical records; in hormonal therapy that affects the metabolism of fat, and suffering from type 2 diabetes mellitus. Subjects agreed to sign the informed consent and they were assured that all information will be confidential. Medical Ethics Commitee from University of Indonesia has approved the study protocol.

\section{Clinical Study}

This study was a randomized, single-blind, parallel design conducted at City Hall of Jakarta in April through May 2015. Subjects who met the study criteria were interviewed to complete the demographic data, physical activity, food intake using semiquantitative FFQ, and anthropometric measurements. Before and after 4 weeks of intervention, subjects were asked to complete food intake data of an estimated 3 days of food intake record of their usual dietary pattern. They were asked to record their food intake of 3 nonconsecutive days : 2 weekdays and 1 day off or non working day, prior to rice bran oil treatment. They were also given a leaflet to help their estimation of food portion sizes.

The subjects were randomly assigned to 1 of 2 groups. One group was assigned to consume 45 $\mathrm{ml} /$ day rice bran oil $(\mathrm{n}=13)$, while another was 15 $\mathrm{ml} /$ day rice bran oil $(\mathrm{n}=13)$. Rice bran oil used for this study was purchased from the market. The oil were manufactured by Pietro Coricelli S.p.a., Italia. The oil was measured and packed into smaller bottles, which were then given to the subjects.. The subjects were asked to consume two bottles of rice bran oil everyday. Compliance was assessed by facilitated researchers. The oil could be consumed with lunch and dinner or be drunk directly. Subjects were asked to not changing their daily diet.. Each subject was asked to consume the rice bran oil once a week until the end of treatment and also be interviewed to determine any complaints while taking the oil.

\section{Laboratory analysis}

Subjects were asked to fast for at least 10 hours prior to blood sampling. Laboratory tests for lipid profile were performed twice, before and after 4 weeks of intervention.. During blood sampling, 3.5 $\mathrm{ml}$ of blood was drawn for the test. Fasting blood samples were collected into tubes and were placed for 30-40 min. Afterwards, blood samples were centrifuged at $1300-3000 \mathrm{~g}$ for $20 \mathrm{~min}$, and then the blood serum were taken for subsequent analysis in laboratory. Total cholesterol and triglycerides serum level were measured by enzymatic methods in an automated biochemistry analyzer. HDL-C values were measured by precipitation and direct methods. LDL was estimated with the Friedewald equations. ${ }^{18}$ Lipid assays were standardized by the Center for Disease Control and Prevention. ${ }^{19}$

\section{Statistical analysis}

Data were analyzed using SPSS version 20 for Windows. Unpaired t-test or Mann-Whitney test was used to compare the data from before and after the study intervention, $\mathrm{p}<0,05$ indicated a statistical difference data from the food intake analyzed with Nutrisurvey 2007 for windows.

\section{RESULTS}

From 26 who initially agreed to participate, 20 subjects completed the 4-week study.. One subject developed illness unrelated to the study and 5 refused to continue the study protocol. Rice bran oil consumption compliance was reported to be greater than $90 \%$ as assessed by self-completed check 
sheets. Baseline characteristics of the subjects are the composition of $48 \%$ carbohydrates, $18 \%$ protein shown in Table 1.

and $37 \%$ fat. There was significant difference in

Table 1. Baseline Characteristic of The Subjects $(n=20)$

\begin{tabular}{lcc}
\hline Variables & $45 \mathrm{ml} /$ day RBO group $(\mathrm{n}=10)$ & $15 \mathrm{ml} / \mathrm{hari}$ RBO group(n=10) \\
\hline Age & $48,90 \pm 5,26$ & $45,70 \pm 6,82$ \\
Height,cm & $164,70 \pm 6,18$ & $164,40 \pm 6,13$ \\
Weight,kg & $75,06 \pm 12,90$ & $73,07 \pm 11,54$ \\
BMI,kg/m ${ }^{2}$ & $27,63 \pm 4,20$ & $26,97 \pm 3,65$ \\
Energy,kkal & $2205,25 \pm 193,53$ & $2071,07 \pm 254,28$ \\
Carbohidrate,g & $281,2 \pm 28,02$ & $266,92 \pm 37,24$ \\
Protein,g & $91,86 \pm 13,21$ & $97,22 \pm 16,96$ \\
Fat,g & $78,78 \pm 11,01$ & $68,73 \pm 13,67$ \\
Fiber,g & $11,06 \pm 0,96$ & $12,25 \pm 3,18$ \\
Total cholesterol,mg/dL & $242,30 \pm 33,66$ & $228,80 \pm 16,96$ \\
LDL cholesterol, mg/dL & $173,70 \pm 46,34$ & $157,10 \pm 25,41$ \\
HDL cholesterol, $\mathrm{mg} / \mathrm{dL}$ & $40,70 \pm 7,02$ & $45,70 \pm 10,06$ \\
Trigliseride, $\mathrm{mg} / \mathrm{dL}$ & $176,50(84-308)$ & $161,00(97-427)$ \\
\hline
\end{tabular}

Values are expressed as mean $\pm \mathrm{SD}$, median(min-max)

The mean age of the $45 \mathrm{ml} /$ day group and 15 $\mathrm{ml} /$ day group were $48.90 \pm 5.26$ and $45.70 \pm 6.82$ years old, respectively. Most of the subjects in this study were classified as in both groups. Physical activity of $45 \mathrm{ml} /$ day group were mostly mild to moderate, and $15 \mathrm{ml} /$ day RBO group were mostly moderate. Most subjects did not have family history of hypercholesterolemia. Also, most of the subjects were non-smokers. The two groups had similar characteristics in terms of age, education level, nutritional status, physical activity, family history of hypercholesterolemia, and smoking history (data not shown).

There was no significant difference in food intake between both groups before treatment. Composition of food intake in $45 \mathrm{ml} /$ day $\mathrm{RBO}$ group was $51 \%$ carbohydrate, $17 \%$ protein and $32 \%$ fat. Composition of food intake in a $15 \mathrm{ml} /$ day RBO group was $52 \%$ carbohydrate, $18 \%$ protein and $30 \%$ fat.

Average calorie intake after 4 weeks of intervention in $45 \mathrm{ml} /$ day $\mathrm{RBO}$ group was 2387 $\mathrm{kcal} /$ day with composition of $46 \%$ carbohydrates, $16 \%$ protein and $43 \%$ fat. Whereas in $15 \mathrm{ml} /$ day RBO group, calorie intake was $2224 \mathrm{kcal} /$ day, with total fat intake after intervention $(p=0,014)$. However, there was no significant difference in energy intake, carbohydrate, protein and fiber after intervention between the two groups. Change of total fat intake $(p=0.007)$ and percentage of fat intake $(p=0,003)$ before and after treatment were also significantly different. Food intake analysis and changes are shown in Table 2.

The decline in serum cholesterol after 4 weeks of intervention was significantly different between both groups $(p=0,049)$. The average changes of cholesterol levels in $45 \mathrm{ml} /$ day $\mathrm{RBO}$ group were $-37,50(-53,00--9,00)$ and in $15 \mathrm{ml} /$ day RBO group was $-10,50(-74,00-4,00)$. Decrease of LDL and triglycerides level were greater in 45 $\mathrm{ml} /$ day RBO group compared to the other group. Levels of HDL increased greater in $45 \mathrm{ml} /$ day RBO group compared to the other group. However, LDL, HDL and triglyceride levels after treatment and changes during treatment were not statistically significant difference between both groups. Lipid profile examination results are shown in Table 3 . Body weight was measured before and after treatment to ensure the safety of RBO intervention 
for 4 weeks. There was no difference of body weight before and after treatment in both groups.

\section{DISCUSSION}

In this study, intervention with additional rice bran oil ( $\mathrm{RBO})$ to the daily diet that contains high fat would affect the food intake proportion of the subjects. There was significant difference in fat

Table 2. Average Daily Intake of Energy, Protein, Fat, Carbohydrate and Fiber at Baseline,_after Intervention and The Changes during Intervention

\begin{tabular}{lcccccc}
\hline \multirow{2}{*}{ Variables } & \multicolumn{2}{c}{$45 \mathrm{ml} /$ day RBO group $(\mathrm{n}=10)$} & \multicolumn{2}{c}{$15 \mathrm{ml} /$ day RBO group $(\mathrm{n}=10)$} \\
\cline { 2 - 7 } & Baseline & Week 4 & Change $(\Delta)$ & Baseline & Week 4 & Change $(\Delta)$ \\
\hline Energy,kkal & $2205,25 \pm 193,53$ & $2205,25 \pm 193,53$ & $182,73 \pm 79,78$ & $2071,07 \pm 254,28$ & $2224,86 \pm 317,38$ & $153,79 \pm 130,30$ \\
Carbohydrate,g & $7,35 \pm 6,24$ & $275,76 \pm 20,89$ & $-5,44 \pm 16,98$ & $266,92 \pm 37,24$ & $267,45 \pm 32,69$ & $0,53 \pm 23,94$ \\
Protein,g & $91,86 \pm 13,21$ & $94,18 \pm 14,15$ & $2,31 \pm 7,81$ & $97,22 \pm 16,96$ & $103,09 \pm 18,53$ & $4,80(0,20-21,50)$ \\
Fat,g & $78,78 \pm 11,01$ & $115,16 \pm 12,05^{*}$ & $36,38 \pm 5,8^{*}$ & $68,73 \pm 13,67$ & $91,56 \pm 23,44$ & $22,82 \pm 12,03$ \\
Fiber,g & $11,06 \pm 0,96$ & $11,48 \pm 0,73$ & $-0,42 \pm 0,84$ & $12,25 \pm 3,18$ & $12,32 \pm 3,08$ & $0,40(-2,30-1,40)$ \\
\hline
\end{tabular}

To our knowledge, this was the first study in Indonesia which compared intervention of rice bran oil with different doses without any change in daily diet to determine the effect of unsaponifiable fractions in both groups. Most of the study subjects were obese with mild-to-moderate physical activity. intake $(\mathrm{p}=0,014)$ between the two groups. Change of fat intake in $45 \mathrm{ml} /$ day RBO group was $15 \%$ and in $15 \mathrm{ml} /$ day $\mathrm{RBO}$ group was $10 \%$. This result shows eventhough the $45 \mathrm{~mL} /$ day $\mathrm{RBO}$ group consumed as much as three times the amount of $\mathrm{RBO}$ compared to $15 \mathrm{~mL} /$ day group, however, the

Tabel 3. Lipid Profile of Research Subjects $(\mathrm{n}=20)$

\begin{tabular}{|c|c|c|c|c|c|c|}
\hline \multirow[t]{2}{*}{ Variables } & \multicolumn{3}{|c|}{$45 \mathrm{ml} /$ day $\mathrm{RBO}$ group $(\mathrm{n}=10)$} & \multicolumn{3}{|c|}{$15 \mathrm{ml} /$ day $\mathrm{RBO}$ group $(\mathrm{n}=10)$} \\
\hline & Baseline & Week 4 & Change $(\Delta)$ & Baseline & Week 4 & Change $(\Delta)$ \\
\hline $\mathrm{TC}(\mathrm{mg} / \mathrm{dL})$ & $242,30 \pm 33,66$ & $207,90 \pm 29,07$ & $-37,50(-53,00--9,00)^{*}$ & $228,80 \pm 16,96$ & $210,70 \pm 26,75$ & $-10,50(-74,00-4,0$ \\
\hline LCL-C (mg/dL) & $173,70 \pm 46,34$ & $157,10 \pm 38,58$ & $-16,6 \pm 11,18$ & $157,10 \pm 25,41$ & $151,60 \pm 24,59$ & $-5,5 \pm 19,36$ \\
\hline $\mathrm{HDL}-\mathrm{C}(\mathrm{mg} / \mathrm{dL})$ & $40,70 \pm 7,02$ & $45,90 \pm 4,77$ & $5,20 \pm 4,52$ & $45,70 \pm 10,06$ & $47,50 \pm 12,17$ & $1,80 \pm 4,39$ \\
\hline $\mathrm{TG}(\mathrm{mg} / \mathrm{dL})$ & $176,50(84-308)$ & $148,50(104-294)$ & $-37,70 \pm 37,65$ & $161,00(97-427)$ & $158,00(105-367)$ & $-20,5 \pm 35,43$ \\
\hline
\end{tabular}

Values are expressed as mean $\pm \mathrm{SD}$, and median (min-max). Values with asterisk $\left(^{*}\right)$ are significantly different from $15 \mathrm{ml} / \mathrm{day}$ RBO group, $\mathrm{p}<0,05 . . \mathrm{TC}$, total cholesterol; LDL-C, low density lipoprotein cholesterol; HDLC, high density lipoprotein cholesterol; TG, triglyceride.

Lack of physical activity stimulates escalation of lipid profiles and blood glucose which independently affect central obesity. ${ }^{20}$ Higher fat and lower fiber intake compared to recommendations can cause hypercholesterolemia and weight gain. Nutritional recommendation for dyslipidemia suggested that fat intake should be around $20-30 \%$ of total calories and fiber around 30 g/day. ${ }^{4,7}$ Consistent to that, food intake data of the subjects in this study showed that unbalanced nutritional intake contributes to hypercholesterolemia and obesity. fat intake difference between both groups was only 14 gram or $5 \%$. This may happened because the subjects who consumed oil $45 \mathrm{ml} /$ day felt full and satisfied faster and longer, which then reduce the consumption of carbohydrates and fat.

This study results showed improvement in lipid profiles, decrease in total cholesterol, LDL and triglycerides as well as increase of HDL level, which are consistent with the previous studies. In several studies previously, gamma oryzanol, phytosterols and vitamin $\mathrm{E}$ in rice bran oil have been reported in some previous studies to have hypocholesterolemic properties. ${ }^{14,15,21}$ Effective 
dose of gamma-oryzanol itself is still unclear until now. Most earlier studies used doses of gammaoryzanol $300 \mathrm{mg} /$ day or, in the form of rice bran oil, 50 grams/day which was included in the daily diet or cooking oil. ${ }^{13,17}$

Research by Eady et al. ${ }^{13}$ used 20 grams of RBO spread (118 mg of phytosterols and $30 \mathrm{mg}$ of gamma-oryzanol) and showed significant improvements in lipid profiles. It showed that administration of small quantities of gammaoryzanol still gave positive results on the lipid profile. A study by Berger et al, ${ }^{22}$ which compare the intervention of gamma-oryzanol $50 \mathrm{mg} /$ day and $800 \mathrm{mg} /$ day in the same amount of RBO (50 grams), showed decreased levels of lipid profile, however the differences were not statistically significant. Adding $18 \mathrm{~g} /$ day of rice bran oil (gamma-oryzanol $40 \mathrm{mg} / \mathrm{dl}$ ) combined with diet for 5 weeks in diabetic significantly lowers total cholesterol and tends to decrease LDL level. ${ }^{23}$ Earlier studies showed that a dose of 0.8-1 g/day of phytosterols can lower LDL level by $5 \% .{ }^{13}$ Related to the doses of RBO, this study found that administration $45 \mathrm{ml} /$ day $\mathrm{RBO}$ led to greater improvements in lipid profiles. It is likely influenced by the amount of unsaponifiable fractions greater in administration of $45 \mathrm{ml} /$ day. According to the data from the RBO manufacturer, there is around $33 \mathrm{mg}$ gamma oryzanol in $15 \mathrm{ml}$ RBO. Therefore, in this study, subjects consumed approximately $33 \mathrm{mg}$ gamma oryzanol in $15 \mathrm{ml} / \mathrm{day}$ RBO group and $100 \mathrm{mg}$ gamma oryzanol in 45 $\mathrm{mg} /$ day RBO group, which both still led to improvement in lipid profile.

Gamma-oryzanol inhibits HMG-CoA reductase enzyme which then lower the level of cholesterol in the liver, therefore, increasing hepatic LDL receptors and the uptake of LDL in the blood. The decrease of LDL level was influenced gammaoryzanol and phytosterol contained in the rice bran oil. The two substances help to increase the expression of hepatic LDL receptors which facilitate reduction in LDL cholesterol, and increase the expression of CYP7A1 which facilitate the catabolism of cholesterol. Phytosterols and gammaoryzanol have also been shown to inhibit the absorption of cholesterol in the body, thus increasing the fecal excretion of cholesterol. ${ }^{17,24,25}$

The percentage of increase of HDL level in $45 \mathrm{ml} /$ day RBO group was $14 \%$, indicating that there was clinically significant increase of positive effect eventhough not statistically significant. Many previous studies regarding administration of RBO in humans had not shown changes in HDL levels. The result of this study is different compared to Berger et $\mathrm{al}^{22}$ which showed no significant difference in HDL levels between the group who received low dose compare to high dose of gamma oryzanol. In this study, greater improvement of other lipid profiles indirectly lead to improvements in HDL value, although not significantly. For safety reason, subjects' body weight were measured before and after treatment. The result showed there was no significant body weight difference in both groups after 4 weeks intervention.

There were some limitations in this study, such as possible errors in recording food intake. Furthermore, the analysis and composition of rice bran oil, factor storage, packaging, and environmental factors, which may influence the effective nutrients in rice bran oil, were not included in the data. This study was only done in male subjects in one community, thus the results of this study generally only could be used in individuals with similar characteristics.

In conclusion, this study showed that consumption of rice bran oil $45 \mathrm{ml} /$ day led to better improvements in lipid profiles compared to 15 $\mathrm{ml} /$ day. Unsaponifiables fractions of rice bran oil had a role in controlling lipid profiles in hypercholesterolemic subjects. Rice bran oil in small dose $(15 \mathrm{ml} /$ day $)$ still improved lipid profiles in hypercholesterolemic males. This study is a preliminary study with a short duration of time, therefore larger sample size and a longer intervention time to observe changes in body composition and lipid profile in the hypercholesterolemic patients is needed. Moreover, to assess the RBO effect in more diverse subject is necessary.

\section{Conflicts of Interest}

No potential conflicts of interest relevant to this article were reported.

\section{Acknowledgment}

The authors acknowledge the support provided for the collection of data by the head and staff in the Health Service Employees,City Hall of Jakarta. The authors acknowledge the support provided by the Department of Nutrition Faculty of Medicine, University of Indonesia. 


\section{REFERENCES}

1. Misra A, Khurana L. Obesity and the metabolic syndrome in developing countries. J Clin Endocrinol Metab 2008;93:S9-30.

2. Kimura E. Indonesia in 2010. Asian Surv 2011;51:186-95.

3. Agency for Health Research and Development Ministry of Health of the Republic of Indonesia. 2010 National Basic Health Research [cited 2015 June 2]. Available from:

http:/www.kesehatan.kebumenkab.go.id/data/lapriskesda s.pdf.

4. Krummel DA. Medical nutrition theraphy for cardiovascular diseases. in: Mahan LK, Escott-Stump S, Janice L, Raymond MVK. Krause's Food and the Nutrition Care Process. Edisi ke-13. Missouri: Elsevier Health Sciences; 2012. p. 833-98.

5. Libby P. The pathogenesis of atherosclerosis. In: Kasper DL, Fauci AS, Longo DL, Braunwald E, Hauser S, Jameson J, editor. Harrison's Principles of Internal Medicine. Edisi ke-16. United States: McGraw-Hill; 2005. p.1425-30.

6. Hatma RD. Lipid profiles among diverse ethnic groups in Indonesia. Acta Med Indones 2011;43:4-11.

7. Third Report of the National Cholesterol Education Program (NCEP) Expert Panel on Detection, Evaluation, and Treatment of High Blood Cholesterol in Adults (Adult Treatment Panel III) Final Report. Circulation 106:314-21.

8. Chitchumroonchokchai C, Adisakwattana S, Ariyapitipun T. Effect of gamma-oryzanol on the bioaccessibility and synthesis of cholesterol. Eur Rev Med Pharmacol Sci 2012:49-56.

9. Henderson AJ, Ollila CA, Kumar A, Borresen EC, Raina $\mathrm{K}$, Agarwal R, et al. Chemopreventive Properties of Dietary Rice Bran : Current Status and Future Prospects. Adv Nutr 2012:643-53.

10. Kozuka C, Yabiku K, Takayama C, Matsushita M, Shimabukuro M. Natural food science based novel approach toward prevention and treatment of obesity and type 2 diabetes: recent studies on brown rice and $\gamma$ oryzanol. Obes Res Clin Pract 2013;7:165-72.

11. Kozuka C, Yabiku K, Sunagawa S, Ueda R, Taira SI, Ohshiro $\mathrm{H}$, et al. Brown rice and its component, $\gamma$ oryzanol, attenuate the preference for high-fat diet by decreasing hypothalamic endoplasmic reticulum stress in mice. Diabetes 2012;61:3084-93.

12. Son MJ, Rico CW, Nam SH, Kang MY. Effect of oryzanol and ferulic acid on the glucose metabolism of mice fed with a high-fat diet. J Food Sci 2011;76:7-10.

13. Eady S, Wallace A, Willis J, Scott R, Frampton C. Consumption of a plant sterol-based spread derived from rice bran oil is effective at reducing plasma lipid levels in mildly hypercholesterolaemic individuals. $\mathrm{Br} J \mathrm{Nutr}$ 2011:1-12.

14. Raghuram T, Rukmini C. Nutritional significance of rice bran oil. Indian J Med Res 1995;102:241-4.
15. Kuriyan R, Gopinath N, Vaz M, Kurpad AV. Use of rice bran oil in patients with hyperlipidaemia. Natl Med J India 2006;18:292-6.

16. Rajnarayana K, Prabhakar MC, Krishna DR. Influence peroxides of rice bran oil on serum lipid and lipids in human subjects. Indian $J$ Physiol Pharmacol 2001;45:442-4.

17. Cicero AF, Gaddi A. Rice bran oil and gamma-oryzanol in the treatment of hyperlipoproteinaemias and other conditions. Phytother Res 2001;15:277-89.

18. Friedewald WT, Levy RI, Fredrickson DS. Estimation of the concentration of low-density lipoprotein cholesterol in plasma, without use of the preparative ultracentrifuge. Clin Chem 1972, 18:499-502.

19. Myers GL, Cooper GR, Winn CL, Smith SJ. The Centers for Disease Control-National Heart, Lung and Blood Institute Lipid Standardization Program. An approach to accurate and precise lipid measurements. Clin Lab Med. 1989, 9(1):105-35.

20. Pescatello L. Low intensity physical activity benefits blood lipids and lipoproteins in older adults living at home. Age Ageing 2000;29:433-39.

21. Zavoshy R, Noroozi M, Jahanihashemi H. Effect of low calorie diet with rice bran oil on cardiovascular risk factors in hyperlipidemic patients. $J$ Res Med Sci 2012;17:626-31.

22. Berger A, Rein D, Schäfer A. Similar cholesterollowering properties of rice bran oil, with varied gammaoryzanol, in mildly hypercholesterolemic men. Eur J Nutr 2005;44:163-73.

23. Lai MH, Chen YT, Chen YY, Chang JH, Cheng HH. Effects of rice bran oil on the blood lipids profiles and insulin resistance in type 2 diabetes patients. $J$ Clin Biochem Nutr. 2012;51:15-8.

24. Chen CW, Cheng HH. A Rice Bran Oil Diet Increases LDL-Receptor and HMG-CoA Reductase mRNA Expressions and Insulin Sensitivity in Rats. $J$ Nurt 2006;136:1472-6.

25. De Smet E, Mensink RP, Plat J. Effects of plant sterols and stanols on intestinal cholesterol metabolism: suggested mechanisms from past to present. Mol Nutr Food Res 2012;56:1058-72. 